\title{
Keselamatan Konstruksi untuk Mencegah Kecelakaan Kerja pada Pekerjaan Perbaikan Flare Stack di PT. Pertamina RU V Balikpapan
}

\author{
Sulardi \\ Program Studi Teknik Sipil,Universitas Tridharma, Balikpapan \\ e-mail: sulardikm61@yahoo.com
}

\begin{abstract}
The number of workplace accidents in the construction industry still occupy the highest rank (31.90\%) and among them are work accident fall from height. The purpose of this study is to provide an overview of the implementation of construction safety in order to prevent the occurrence of work accidents on construction improvement work carried out diketinggian. The research method used is the method of application research with case study approach method ie damage to construction and flare stack equipment at PT. Pertamina RU V Balikpapan. The results showed that the success of preventing accidents and achieving zero incident in PT. Pertamina is always inculcate to all workers to think safety first, do the job safely and finish the job safely.
\end{abstract}

Keywords: Work at heigh, safety first, zero incident.

\begin{abstract}
Abstrak
Angka kecelakaan kerja dilingkungan industry konstruksi masih menduduki ranking tertinggi $(31.90 \%)$ dan diantaranya adalah kecelakaan kerja jatuh dari ketinggian. Tujuan penelitian ini adalah memberikan gambaran penerapan keselamatan konstruksi untuk mencegah terjadinya kecelakaan kerja pada pekerjaan perbaikan konstruksi yang dilakukan diketinggian. Metode penelitian yang digunakan adalah metode penelitian aplikasi dengan metode pendekatan studi kasus yakni kasus kerusakan pada konstruksi dan peralatan flare stack di PT. Pertamina RU V Balikpapan. Hasil penelitian menunjukan bahwa keberhasilan mencegah kecelakaan kerja dan mencapai zero incident dilingkungan PT. Pertamina adalah dengan selalu menanamkan kepada semua pekerja untuk berfikir safety first, melakukan pekerjaan dengan selamat dan menyelesaikan pekerjaan dengan selamat.
\end{abstract}

Kata kunci :bekerja di ketinggian, safety first, zero incident.

\section{Pendahuluan}

\subsection{Latar Belakang Masalah}

Menurut data BPJS ketenagakerjaan, sampai dengan Nopember 2016 jumlah kecelakaan kerja dengan korban meninggal dunia adalah 2.382 orang, dimana kecelakaan tertinggi terjadi di sektor industri konstruksi dengan 31,90\% kecelakaan dan dari penyebab yang terttinggi adalah terjatuh dari ketinggian dengan 26\% (Jakarta,
Kompas, com; 09.11.2016). Ini bukan prestasi yang membanggakan bagi dunia konstruksi tetapi merupakan keprihatinan tersendiri. Betapa tidak karena dunia konstruksi adalah pengemban amanah Undang-undang Jasa Konstruksi RI No.2 Tahun 2017[1] diantaranya mengamanatkan bahwa (1) pembangunan nasional bertujuan mewujudkan masyarakat adil dan makmur yang berdasarkan pancasila dan UndangUndang Dasar 1945 (2) sektor jasa 
konstruksi merupakan kegiatan masyarakat mewujudkan bangunan yang berlungsi sebagai pendukung atau prasarana aktivitas sosial ekonomi kemasyarakatan guna menunjang terwujudnya tujuan pembangunan nasional (3) pekerjaan konstruksi adalah keseluruhan atau sebagian kegiatan pembangunan, pengoperasian, pemeliharaan, pembongkaran, dan pembangunan kembali.

Namun dengan hal diatas tidaklah menjadi vonis bahwa setiap pekerjaan konstruksi diketinggian identik dengan korban kecelakaan kerja dan meninggal dunia. Seolah-olah pada pekerjaan konstruksi di ketinggian selalu ada tumbal yang harus dikorbankan, hal ini sangat tidak benar dan sangat tidak beralasan. Fakta ini dibuktikan di lingkungan industri Migas-PT. Pertamina RU V yang setiap periodik melakukan pekerjaan perbaikan konstruksi dan peralatan kilang yang posisinya diketinggian namun tidak terjadi kecelakaan kerja dan justru menambah pencapaian jam kerja aman tanpa incident.

Berkaca dari fakta tersebut penelitian ini dilakukan dalam rangka menemukan jawaban mengapa pekerjaan perawatan dan perbaikan konstruksi dn peralatan kilang PT. Pertamina yang posisinya diketinggian dapat diselesaikan dengan baik dan aman, tepat waktu, tepat biaya dan tepat mutu (ontime, on budget, on specification).

Bagi pekerja yang tidak terbiasa bekerja dan tidak berpengalaman bekerja diketinggian akan mengalami beban psikologis berupa rasa takut, kepala menjadi pusing, kelelahan, dehidrasi, kehilangan keseimbangan dan yang fatal adalah terjatuh dari ketinggian. Untuk kemudahan dan terarahnya penelitian, maka permasalahan penelitian dirumuskan : Jika pekerjaan diketinggian dilakukan dilakukan sesuai dengan hirarki, metode kerja, regulasi dan standard operation prosedure (SOP) maka pekerjaan diketinggian dapat diselesaikan dengan baik dan aman tanpa kecelakaan (zero incident).

Agar lingkup penelitian fokus pada penyelesaian masalah, penelitian ini membatasi diri pada :

1. Pekerjaan diketinggian meliputi pekerjaan perbaikan konstruksi flatform metal grating flare stackpada ketinggian 6.5meter sampai ketinggian 71meter

2. Pekerjaan regreasing guy wire rope sebanyak sembilan set pada elevasi 21meter, 42 meter dan 67 meter

3. Pekerjaan perbaikan di area flare stack kilang Balikpapan I dilaksanakan dalam rangka Turn Around (plant stop).

\subsection{Tujuan dan Manfaat Penelitian}

Tujuan yang hendak dicapai melalui penelitian ini adalah :

a. Memberikan gambaran tahapan pelaksana an pekerjaan perbaikan konstruksi flare stack kilang Balikpapan I yang dilakukan di ketinggian

b. Memberikan gambaran potensi bahaya dan langkah-langkah pencegahannya pada pekerjaan perbaikan flare stack di kilang Balikpapan I.

Dari hasil penelitian ini diharapkan dapat menemukan jawaban atas pertanyaan penelitian terkait dengan bahaya-bahayadan langkah-langkah pencegahannya pada pelaksanaan pekerjaan konstruksi flare stack yang dilakukan di ketinggian.

\section{Konstruksi flare stack}

Flare stack adalah menara obor yang berfungsi untuk membakar off specification gas (offgas) yang berasal unit pengolahan minyak (crude distilation unit) [5] sehingga pada saat dilepaskan ke lingkungan udara terbuka kondisi off gas telah aman (dalam ambang batas) dan tidak mencemari lingkungan udara. Dalam hal ini flare stack memiliki fungsi sebagai alat konservasi lingkungan udara. 
Spesifikasi konstruksi flare stack kilang Balikpapan I sesuai job specification No. 1569 JG Doc. 1569-001 [3,4,5]adalah sebagai berikut.

a. Type flare stack : Guy wire support guyed

b. Tag No. Equipment : V-219-01

c. Tinggi total : 71 meter, mulai dari pondasi

d. Spesifikasi material riser : Seamless pipe steel dia. 42 Inch, tebal. $12 \mathrm{~mm}$

e. Spesifikasi guy wire : Wire rope diameter $20 \mathrm{~mm}$

f. Sumber pengapian : Pilot gas with ignator system

g. Berat total : 27,50 tons

h. Verticality/ ketegakan : 1/500 L (0.25\%)

i. Bordes : Platform metal grating with steel support, guard rails, handrails, ladder casges, fencing dan warning barriers.

Peralatan operasi flare stack system terdiri dari beberapa peralatan penunjang meliputi knock out drum (KOD), pompa condensate, pipa transfer line, riser flare stack, flame flare stack, pilot gas, guy wire rope dan deadman anchor set. Operasi offgas dari KOD mengalir secara alamiah ke flame flare stack dan dibakar secara automatis dengan pilot yang selalu menyala sehingga offgasdapat terbakar sempurna.

\section{Keselamatan kerja konstruksi diketinggian}

Keselamatan kerja konstruksi di ketinggian bertujuan untuk (1) mengenalkan dan memahami prosedur operasi standar (SOP) bekerja diketinggian (2) mengetahui dan mengendalikan resiko untuk bekerja diketinggian (3) mengerti dan memahami bahaya-bahaya bekerja diketinggian (4) mengetahui dan memahami tata cara menggunakan peralatan pencegah kecelakaan dan pelindung jatuh dari ketinggian.

Faktor penyebab dominan kecelakaan kerja diketinggian adalah faktor orang dan faktor lingkungan kerja. Penyebab dominan kecelakaan kerja diketinggian adalah kondisi sub stabdard, rusak, unsafe action dan unsafe condition[2]. Faktor dan penyebab tersebut diantaranya adalah (1) kondisi lingkungan yang meliputi angin, hujan dan licin (2) kondisi lingkungan yang menyebabkan terpeleset, tersandung dan terjatuh (3T) (3) adanya kerusakan bagian konstruksi dan peralatan (4) penggunaan peralatan yang tidak sesuai dan tidak benar (5) kekacauan fikiran, stres, nervous dan tindakan terburu-buru (6) penyebab lain yang disebabkan oleh kondisi dan lingkungan kerja.

Hal yang penting untuk melakukan pekerjaan diketinggian dengan selamat adalah meliputi (1) evaluasi tempat kerja (2) identifikasi bahaya-bahaya terjatuh dari ketinggian yang mungkin terjadi (3) evaluasi proses kerja yang akan dilakukan (4) menentukan metode pelindung jatuh dari ketinggian yang akan digunakan untuk setiap bahaya yang teridentifikasi, dan (5) memberikan sosialisasi dan pelatihan bekerja aman bagi para pekerja.

Pada dasarnya potensi bahaya terjatuh dari ketinggian terdapat pada semua jenis dan lokasi pekerjaan diketinggian antara lain (1) pekerjaan dipinggir tebing atau lereng konstruksi (2) tempat bekerja terbuka dengan sisi yang tidak terjaga (3) pekerjaan penggalian dan lubang galian (4) daerah operasi pengangkatan (5) pekerjaan diatas atap, pemancangan tiang pancang dan konstruksi bangunan (6) lokasi kerja dekat poros dan penggalian struktur yang tidak stabil, dan (7) lokasi kerja yang dekat permukaan rapuh atau getas[2,6].

Tindakan pencegahan kecelakaan saat bekerja diketinggian dilakukan dengan (1) hindari bekerja diketinggian saat cuaca buruk, hujan, angin kencang, saat sedang sakit dan saat tidak dalam fokus konsentrasi (2) jika mengetahui adanya kemungkinan bahaya terpeleset, tersandung dan terjatuh agar segera dihindari (3) gunakan peralatan keselamatan kerja dan alat pelindung diri yang cocok dan sesuai sejak bekerja pada ketinggian 1,2 meter dan yang lebih tinggi. 


\section{Strategi pengendalian bahaya kerja konstruksi di ketinggian}

Terdapat tiga strategi pokok untuk mengendalikan bahaya bekerja diketinggian dengan (1) metode pengendalian rekayasa (2) metode pengendalian administrasi dan (3) penggunaan alat pelindung diri[5]. Metode pengendalian rekayasa dengan cara mendesain ulang dan mengganti peralatan atau tempat kerja yang rusak sehingga terhindar dari bahaya jatuh, cara yang paling sederhana adalah dengan cara memindahkan pekerjaan yang seharusnya dilakukan diatas dipindahkan lokasi kebawah, gunakan akses masuk permanen seperti tangga, walkway, platform sementara, perancah, pagar, jaring pengaman jatuh, kanopi, tutup atas dan jaring untuk mencegah tertimpa benda jatuh dari atas. Metode pengendalian administrasi meliputi mengurangi durasi, frekwensi dan keparahan paparan bahaya, membuat dan menerapkan tata cara kerja yang aman dan melakukan pelatihan, pengkondisian pekerja, periode penyesuaian, pengawasan berkala, perawatan dan modifikasi. Sedangkan pengendalian dengan alat pelindung diri meliputi penggunaan alat pelindung diri yang cocok dan sesuai, pekerja menggunakan sistim penahan jatuh dengan benar, dan alat pelindung diri adalah alat mencegah kecelakaan yang paling akhir.

\section{Metode Penelitian}

\subsection{Metode Pendekatan}

Penelitianiniadalah penelitian terapan dengan metode pendekatan studi kasusmencegah kecelakaan kerja pada pekerjaan perbaikan flare stack kilang Balikpapan Iyang dilakukan diketinggian 71 meter [4,5]dengan lingkungan kerja terbatas dan waktu pelaksanaan yang ketat pada kesempatan turn around kilang PT.Pertamina Balikpapan I. Keberhasilan dalam pelaksanaan pekerjaan tanpa kecelakaan ini merupakan success story yang dapat direplikasi untuk melakukan pekerjaan sejenis ditempat lain.

\subsection{Bahan digunakan}

a. Metal grating dengan spesifikasi standard ANSI/NAAM HMAA MBG 531-09

b. Baja profil dengan spesifikasi WF 100, C 100 dan L 75.

c. Guy wire rope, dia. $24 \mathrm{~mm}, 9$ set

d. Padeyes platetebal $16 \mathrm{~mm}$

e. Shacke clips type omega, kapasitas. 5 ton

f. Material grease dengan spesifikasi high duty dan high temperatuture resistance

g. Bahan-bahan lain sesuai kebutuhan disite.

\subsection{Peralatan digunakan}

a. Mesin las, mesin potong dan gergaji

b. Mesin las listrik dan kelengkapannya

c. Alat greasing guy wire

d. Seling/ wire rope (sling) type strand core rope dia. $3 / 4$ inch

e. Perancah dan tangga kerja

f. Guy wire tension test

g. Air winch, kapasitas angkat. 5 ton.

\subsection{Metode kerja perbaikan platform}

a Siapkan material metal grating dan lakukan fabrikasi sesuai dengan bentuk dan dimensi disite

b. Lakukan perbaikan pada steel suport platform, ganti jika dimensi telah berubah

c. Angkat metal grating dengan alat angkat davit sampai elevasi pemasangan platform

d. Pasang platform dengan konfigurasi sesuai kondisi disite

e. Bersihkan detail konstruksi dan lokasi kerja yang dianggap sudah tidak perlu

f. Lakukan preparasi dan coating dengan spesifikasi material mastic tolerance coat dengan tebal min. 200 micron DFT

\subsection{Metode kerja regreasing guy wire rope}

a. Pasang shackle clips dan katrol disisi atas dan bawah untuk route sling penarik alat greasing, pastikan rol berfungsi dengan baik dan aman

b. Pasang alat greasing, pastikan telah diisi dengan material grease sesuai spesifikasi 
dan pastikan pula alat grease pada keadaan seimbang

c. Tarik alat greasing keatas untuk proses greasing langkah 1, tarik kebawah alat greasing untuk langkah kedua, pastikan seluruh permukaan guy wire rope telah terlumasidengan baik

d. Pindah ke posisi guy wire yang lain dan lakukan sebagaimana langkah no.a sampai langkah no.c sehingga seluruh guy wire flare stack selesai dilumasi seluruhnya.

e. Lanjutkan dengan resetting guy wire terpasang dengan alat guy wite tension gauge, pastikan tegangan guy wire pada kondisi aman dan riser flare stack pada verticalty safe.

\section{Hasil dan Pembahasan}

\subsection{Hasil Penelitian}

\section{Pekerjaan perbaikan flare stack}

Pekerjaaan yang telah dilakukan pada tahap persiapan pekerjaan perbaikan platform flare stack meliputi persiapan peralatan, persiapan tenaga kerja, persiapan alat-alat keselamatan kerja dan alat pelindung diri, persiapan surat ijin kerja (work permite), fabrikasi platform pengganti sesuai spesifikasi standard metal grating plate steel galavanized ANSI/ NAAMM HMAA MBG 531-09[3], pemasangan scaffolding dan pemasangan air winch dan katrol. Pekerjaan persiapan keselamatan kerja meliputi pengaturan bentuk, konfigurasi, pemeriksaan dan pemberian tagging pada scaffold dan rigger, pengaturan perlengkapan kerja dan peralatan keselamatan kerja, HSE Plan dan environmental plan yang menegaskan bahwa pekerjaan perbaikan flare stack yang dilakukan mulai ketinggian 6,5 meter sampai dengan ketinggian 71 meter diatas permukaan tanah dan area kerja dibawahnya berada pada kategori high risk dengan potensi bahaya terjatuh dari ketinggian, tertimpa material, tertimpa peralatan dan terjepit benda keras pada saat melakukan handling telah teridentifikasi, telah tersedia precaution-nya dan telah tertulis pada lembar job safety analysis sebagai lampiran ijin kerja aman diketinggian.

Pelaksanaan perbaikan flare dengan status pekerjaan very urgent meliputi pekerjaan perbaikan dan penggantian metal grating yang rusak telah diganti dengan metal grating baru dengan spesifikasi ANSI/NAAM HMAA MBG 531-09 dengan bentuk, dimensi dan konfigurasi terpasang telah sesuai kriteria quality assurance dan dapat diselesaikan tepat waktu, tanpa terjadi kecelakaan kerja (zero incident).

\subsection{Pekerjaan regreasing guy wire flare stack}

Pekerjaaan yang telah dilakukan pada tahap persiapan meliputi peralatan kerja, material kerja, alat keselamatan kerja, alat pelindung diri, surat ijin kerja dan alat bantu lain sesuai kebutuahn di site. Guy wire yang di-regreasing adalah guy wire rope type IWRC x WL diameter 25 meter dengan panjang total 450 meter dengan sudut kemiringan slope. $32,5^{\circ}-62,5^{\circ}$ dan mengacu kepada drawing No.1569011/016/017 Rev.4 [4]dengan spesifikasi material grease yang dipergunakan adalah medium heavy duty dengan service temperature min. $45^{\circ} \mathrm{C}$. Pekerjaan regreasing guy wire rope flare stack ini dilakukan sesuai standar bahwa material guy wire rope flare stack harus selalu terpelihara dan tidak diperbolehkan mengalami korosi (degradasi material). Aspek keselamatan kerja yang telah disiapkan meliputi pengaturan tata letak, bentuk dan konfigurasi scaffolding, pengaturan peralatan kerja, pengaturan peralatan keselamatan kerja dan peralatan environmental protection (HSE Plan) yang menegaskan bahwa pekerjaan regreasing guy wire rope flare stack pada ketinggian 21 meter sampai 71 meter dan lokasi dibawah area kerja adalah pada kategori high risk dengan potensi bahaya terjatuh dari ketinggian, tertimpa material dan peralatan dan terjepit benda keras pada saat melakukan handling material dan peralatan telah 
teridentifikasi, telah tersedia precautionnya dan telah tertulis pada lembar job safety analysis sebagai lampiran ijin kerja aman diketinggian.

Pelaksanaan regreasing guy wire flare stack dengan status pekerjaan very urgent yang dilaksanakan pada kesempatan turn around kilang Balikpapan I meliputi greasing sebanyak 9 set guy wire dia. $25 \mathrm{~mm}$ dan sepanjang 450 meter dengan spesifikasi material medium heavy duty grease sehingga melapis seluruh permukaan guy wire, turn buckle, shackle clips, baut-baut angker dan baut-baut pengikat base plate flare stack. Greasing guy wire diawali dengan membersihkan karat dipermukaan dan dilanjutnya dengan regreasing dengan alat greasing sehingga seluruh permukaan guy wire terlapis dengan grease seluruhnya dengan cara mengulang pergerakan naik dan turun alat greasing masing-masing guy wire tiga kali. Untuk memastikan hasil greasing telah sesuai prosedur kerja No.TKI-C006/E15143/2012-S0[5], QC/QA No.029/RMPP/15142/2012 [5]dengan hasil bahwa pekerjaan yang dikerjakan telah sesuai spesifikasi standar dan dinyatakan dapat diterima.

Keberhasilan implementasi K3 konstruksi pada pekerjaan perbaikan flare stack Kilang Balikpapan I telah direplikasi untuk pekerjaan sejenis di Kilang Balikpapan II dan terbukti berhasil dengan baik, tidak terjadi kecelakaan kerja, zero incident. Keberhasilan hasil penelitian keselamatan konstruksi di ketinggian ini juga telah dipresentasikan pada seminar regional dalam K3 konstruksi yang diselenggarakan oleh Himpunan Mahasiswa Jurusan Teknik Sipil Politeknik Negeri Balikpapan pada tanggal. 19 Nopember 2017 di Adhika Hotel Bahtera Balikpapan.

\subsection{Pembahasan}

Strategi yang diterapkan pada pekerjaan diketinggian untuk perbaikan flare stack ini kontraktor pelaksana pekerjaan telah menyiapkan langkah-langkah untuk mencegah kecelakaan kerja dan mencegah bahaya terjatuh dari ketinggian berupa lima langkah hirarki bekerja aman diketinggian yang meliputi (1) menggunakan kualifikasi tenaga kerja yang sesuai, berpengalaman melakukan pekerjaan di ketinggian, berperilaku aman dan bekerja pada kondisi aman serta memiliki tanggung jawab penuh atas pekerjaannya (2) memahami dengan baik apa saja yang akan dilakukan, apa yang harus dilakukan, dimana pekerjaan dilakukan, peralatan apa saja yang akan digunakan, potensi bahaya dan langkah pencegahannya (3) mengidentifikasi bahaya disekitarnya tempat kerjanya dan langkajlangkah pengendaliannya dalam job safety analysis (4) menentukan strategi dan rencana penyelamatan (escape way) jika terjadi kondisi emergency kepada pekerja diketinggian dan memastikan pekerja telah menggunakan fall restraint dengan benar (5) membuat rencana pengendalian darurat terhadap pekerja yang mengalami kecelakaan, terluka dan memerlukan pertolongan medis.

Pada pekerjaan perbaikan flare stack Kilang Balikpapan I yang dilaksanakan pada kesempatan turn around bersamaan dengan beberapa jenis pekerjaan yang berbeda dan oleh kontaktor pelaksana yang berbeda sangat mungkin terjadi kecelakaan kerja dan kecelakaan kerja terjatuh dari ketinggian, namun pada pekerjaan perbaikan flare stack ini tidak terjadi kecelakaan kerja atau terjatuh dari ketinggian. Tugas dan tanggung jawab pengawas, suprvisor dan kepala kerja adalah mengidentifikasi bahaya, resiko dan menentukan langkah pengendaliannya, mengkomunikasikan cara pengendalian bahaya dan resiko kerja, mengawasi dan melakukan pengawasan agar semua pekerja didalam pengawasan patuh didalam berperilaku kerja aman. Tugas dan tanggung jawab petugas safety meliputi identifikasi aspek legal dan syarat-syarat kerja aman, menyiapkan sarana kerja aman. Sedangkan tugas dan tanggung jawab 
pekerja di ketinggian adalah mematuhi semua tata cara kerja, prosedur kerja aman dan pengendalian yang telah ditetentukan.

Pencapaian jam kerja aman yang dicapai oleh kontraktor pelaksana pekerjaan perbaikan flare stack Kilang Balikpapan I yang memperkerjakan 18 orang pekerja selama 14 hari kerja adalah telah menyumbangkan 2.520 jam kerja aman tanpa kecelakaan kerja (zero incident). Langkah-langkah tersebut selanjutnya dibuat dalam bentuk check list yang setiap akan memulai pekerjaan dan selesai pekerjaan dilakukan check list yang dilakukan oleh Safety Inspector - HSE dan disaksikan oleh Pengawas area dan Inspection Engineer.

\section{Kesimpulan}

a. Faktor dan penyebab dominan kecelakaan kerja diketinggian pada pekerjaan perbaikan flare stack diarea kilang Balikpapan I meliputi faktor orang dan lingkungan kerja, sedangkan penyebab kecelakaan kerja diketinggian adalah kondisi sub stabdard, kondisi konstruksi rusak, unsafe condition dan tindakan pekerja yang unsafe action

b. Tahapan bekerja aman diketinggian meliputi pemilihan kualifikasi tenaga kerja yang sesuai dan berpengalaman melakukan pekerjaan di ketinggian, memahami ruang lingkup pekerjaan yang akan dilakukan, mengidentifikasi potensi bahaya disekitarnya tempat kerjanya, menentukan strategi dan rencana penyelamatan jika terjadi kondisi emergensi dan mengkomunikasikan rencana tindakan darurat bila ada pekerja yang mengalami kecelakaan, terluka dan memerlukan pertolongan medis.

\section{Saran}

a. Faktor dan penyebab dominan kecelakaan kerja diketinggian meliputi faktor orang dan lingkungan kerja dan sedangkan penyebab kecelakaan kerja diketinggian yang meliputi kondisi sub stabdard, kondisi konstruksi rusak, unsafe condition dan tindakan pekerja yang unsafe action dapat menjadi guidance awal pada saat mengidentifikasi bahaya dan langkahlangkah pengendaliannya pada pekerjaan konstruksi di ketinggian

b. Tahapan bekerja aman diketinggian meliputi pemilihan kualifikasi tenaga kerja yang sesuai dan berpengalaman, memahami ruang lingkup pekerjaan dan metode kerjanya, mengidentifikasi potensi bahaya dilingkungan kerjanya, menentukan strategi dan rencana penyelamatan pada kondisi emergensi dan mengkomunikasikan rencana tindakan darurat pertolongan serta tindakan medis dapat direplikasi sebagai panduan bekerja aman untuk pekerjaan sejenis ditempat lain.

\section{Ucapan Terima kasih}

Dengantelahselesainyapenelitianini dalansebagai catatan succes storydalam rangka mencegah kecelakaan kerja di ketinggian pada pelaksanaan pekerjaan perbaikan flare stack di Kilang Balikpapan PT. Pertamina, disampaikan ucapan terimakasih kepada Bapak Agus Sugiana dari BPPT, Bapak Edward Hartono dari PT. Punjas dan Bapak Rahendrafedy dari Stationary Inspection Engineer PT. Pertamina RU V yang telahbanyak membantu dan mensupport kelancaran penelitian ini.

\section{Daftar Pustaka}

[1]. Undang-Undang Republik Indonesia No.2 Tahun 2017, Tentang Jasa Konstruksi, Lembaran Negara Republik Indonesia Tahun 2017 Nomor.11

[2]. Catalogue No. 1321 Guide, 2006, Safe Work At Heights, WorkCover Publications Hotline, New South Wales

[3]. JGC Corporation, 1996, Flare stack V219-01 Data Sheet Job No.1569 JG 
Document No.1569-001 Balikpapan Refinery I Upgrading Project, Nipon National Airoil Burner Corporation Ltd, Japan

[4]. Sulardi, 2015, Mempercepat Pemasangan Guy Wire Flare Stack V19-01 Dengan Alat Bantu Roll Geser dan Air Winch di $R U V$ Balikpapan, Portal Sharing Knowlwege PT. PertaminaCorporate, Jakarta;http://ptmkpwab81.Pertamina.co m/komet/searchResult.aspx?, Kodefikasi. AB 9999
[5]. Sulardi, 2014, Implementasi Keselamatan Kerja Konstruksi Di Ketinggian Pada Pekerjaan Menera Obor Di Kilang Balikpapan II PT. Pertamina RU V Balikpapan, Laporan Penelitian Universitas Tridharma Balikpapan, Non Publikasi.

[6]. The Hongkong Construction Association, 2005, Construction Site Safety Handbook, The real Estate Developers Association of Hongkong. 